\title{
Coupling of the Localized Wind Wall at High Latitudes to the Lower Thermosphere by Neutral Cells
}

\author{
Vin Bhatnagar \\ Center for Research in Earth and Space Science, Physics department, York University, Toronto, Canada
}

Email address:

vinbhatnagar1@hotmail.com

\section{To cite this article:}

Vin Bhatnagar. Coupling of the Localized Wind Wall at High Latitudes to the Lower Thermosphere by Neutral Cells. International Journal of Astrophysics and Space Science. Vol. 8, No. 3, 2020, pp. 27-31. doi: 10.11648/j.ijass.20200803.12

Received: October 22, 2020; Accepted: November 7, 2020; Published: November 19, 2020

\begin{abstract}
The recently observed Wall in the daytime zonal winds in the thermosphere from $O\left({ }^{1} \mathrm{~S}\right)$ and $O\left({ }^{1} \mathrm{D}\right)$ emissions by the WINDII instrument on the UARS satellite in the high latitudinal region during 1994 to 1996, has been interpreted in terms of NCAR-TIGCM models. The strong westward polar wind (convergence) and weaker eastward winds equator wards of it (divergence), potentially generating localized vertical flows, overlap the dayside high density and equatorward of it low density neutral Cells' regions in the models. The models indicate that the Cells and the Wall separating them exist at all solar and geomagnetic activities. These Cells in the thermosphere can transport neutral gas vertically down in the convergence region and up in the divergence region thus moving the associated emissions as observed in the data. Since the diameter of these Cells can reach up to $2000 \mathrm{~km}$, the resulting enhanced emissions may have scale size of about $20^{\circ}$ in latitude and longitude. The idealized transport time is under 8 minutes for up to $100 \mathrm{~km}$ for these observations during quiet solar and geomagnetic conditions. Once the transporting Cell's temperature / density reaches that of the ambient atmosphere they disappear and other Cells will partake in this process at these latitudes and times.
\end{abstract}

Keywords: Ionosphere, Thermosphere, Neutral density Cells, Atomic oxygen emissions, Windii-UARS

\section{Introduction}

In a recent work [13], a zonal wind reversal in the 140 to $250 \mathrm{~km}$ range from westward polar cap winds to equatorward weaker eastward winds was observed in the $60^{\circ}-70^{\circ}$ geographic latitudinal range and the $100^{\circ}-200^{\circ}$ longitudinal range in the southern hemisphere in $\mathrm{O}\left({ }^{1} \mathrm{~S}\right)$ daytime observations from the Wind Imaging Interferometer (WINDII) on Upper Atmospheric Research Satellite (UARS). The corresponding observations in the northern hemisphere were in the same latitudinal range, but in the $200^{\circ}-300^{\circ}$ longitudinal range. In southern hemisphere, the observational period from March, 11 to 20, 1996 was during low solar activity (F $\left.10.7 \sim 70 \times 10^{-11} \mathrm{w} / \mathrm{m} 2 / \mathrm{c} / \mathrm{s}\right)$ and low geomagnetic activity $(\mathrm{Ap}<15)$, being unsettled on March, 11 and 21 $(23<\mathrm{Ap}<28)$. In the northern hemisphere, the observations were from October 2 to 10,1995 . The solar activity was also low $\left(\mathrm{F} 10.7 \sim 71 \times 10^{-11} \mathrm{w} / \mathrm{m} 2 / \mathrm{c} / \mathrm{s}\right)$, but the geomagnetic activity was moderately disturbed $(16<\mathrm{Ap}<58)$. The upper atmospheric observation in summer solstice, January, 1995 in Red line emission $\left[\mathrm{O}\left({ }^{1} \mathrm{D}\right)\right.$ at $\left.630 \mathrm{~nm}\right]$ from WINDII in the southern hemisphere for low solar and mild geomagnetic activity have also been recently reported by Shepherd et al [14]. They observed an increase in the emissions at around $200 \mathrm{~km}$ in the $100-150^{\circ} \mathrm{E}$ longitudinal zone at high latitudes. The regions observed lie below the cusp region which resides at about $78^{\circ}$ geomagnetic and ultimately merges with the auroral oval. This sharp reversal region was termed as a 'Wind wall'. This reversal created a convergence on the west side wind and a divergence equatorward of the wall on the east side wind. As a result of these convergence / divergence regions and the presence of air Cells in this region, vertical downward / upward motion in the neutral gas will occur as observed in the observations. The emissions were enhanced to lower altitudes on the west side wind (convergence) region and increased in altitude on the east side wind (divergence) of the wall.

Schoendorf et al and Crowley et al have investigated neutral density at polar latitudes in both hemispheres in the $130-350 \mathrm{~km}$ range during high and low solar activity periods, utilizing the Thermospheric Ionospheric General Circulation Model (TIGCM) of the National Center for 
Atmospheric Research (NCAR) [3, 11, 12]. The model simulations were carried out to predict the density perturbations observed by S85-1 satellite near $200 \mathrm{~km}$. They found high density cells in the thermosphere near local noon around $70^{\circ}$ and low density cells equatorward around $60^{\circ}$ geographic for low geomagnetic conditions. The Cells moved to lower latitudes for high geomagnetic activities and the number of Cells gradually increased to 3 (a high Cell near midnight), then to 4 (a low density Cell near dusk) and the winds are strengthened. Cells of enhanced temperature and pressure were also predicted. These high and low density Cells are the result of the velocity structure as a result of the combination of the joule heating, ion-drag, Coriolis and pressure-gradient forces. Below about $170 \mathrm{~km}$, there are only 2 Cells. Above about $170 \mathrm{~km}$, the neutral velocity is cyclonic (anticlockwise) in a low density Cell. In the high density Cell, it is anticyclonic (clockwise). This will imply a westward wind in the high density Cell and an eastward wind in the low density Cell near the Wall separating the two. The Cell structures in the north and southern hemispheres are similar except that they are located at slightly lower latitudes in the southern hemisphere and slightly offset from the positions in the northern hemisphere, for similar solar and geomagnetic activity. This difference was attributed to the fact that the Cell structures are fixed to the magnetic poles in their hemispheres which are symmetrically offset. In the WINDII observations, the Wall in the southern hemisphere was between $100-200^{\circ}$ longitude for relatively quiet geomagnetic conditions, and between $200-300^{\circ}$ longitudinal ranges in the northern hemisphere for active geomagnetic conditions. The density structure of the Cells extends from about $140 \mathrm{~km}$ to about $300 \mathrm{~km}$ and possibly below $400 \mathrm{~km} \mathrm{[6]} \mathrm{for} \mathrm{all} \mathrm{solar} \mathrm{and} \mathrm{geomagnetic} \mathrm{activities.}$ These Cells have been observed by many satellites: ESRO-4 and DE2 [1], SETA-1 [8], S85-1 [3]. The diameters of the Cells may range upward from about $1000 \mathrm{~km}$, depending on the solar and geomagnetic activity.

Figure 1(a, b, c) depicts the Cells' contours with local time in neutral mass density at $200 \mathrm{~km}$ arising from the wind structure for the low, medium and high geomagnetic activity respectively in the northern hemisphere [3]. Geomagnetic quiet, moderate and active conditions were represented with Cross polar cap potentials of 30,60 , and $90 \mathrm{kv}$ respectively. If we take the longest contour line in the polar plots depicted by arrows, separating the high density and low density Cells to be the possible representative of the Wall position, then it can be seen that its position changes from roughly East-West aligned to more latitudinally North-South aligned as the geomagnetic activity represented by the cross polar cap potential difference increases (Figure 1b, c). In the lower thermosphere at $140 \mathrm{~km}$ (Figure 1d), the Wall seems to be aligned approximately East-West for all solar and geomagnetic conditions (Figure 1 in [11]).

A reversal of the wind direction close to the edge of the auroral zone indicating a cellular type of thermospheric circulation was indicated as early as in 1956 by DeVries from Logacs, the low altitude Air Force satellites' experiment [9].
Up to $40 \%$ density variation could occur from low to high density Cells, depending on the solar and geomagnetic activity within 1-2 hours [3].
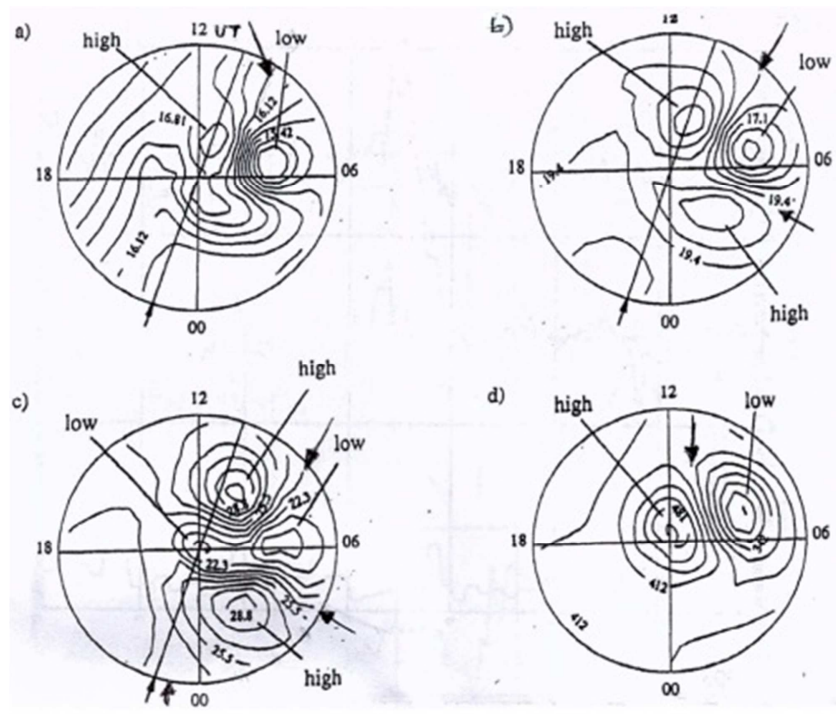

Figure 1. Neutral Mass Density Cells.

NCAR-TIGCM prediction of neutral mass density for low solar activity in geographic coordinates for 12 UT (Local noon) for (a) $200 \mathrm{~km}, 30 \mathrm{kV}$; (b) $200 \mathrm{~km}, 60 \mathrm{kV}$; (c) $200 \mathrm{~km}, 90 \mathrm{kV}$; (d) $140 \mathrm{kV}, 90 \mathrm{kV}$. Satellite S85-1 trajectory at $200 \mathrm{~km}$ is superposed. Outer circle corresponds to $45^{\circ} \mathrm{N}$ and density is in $10^{-14} \mathrm{gm} / \mathrm{cm}^{3}$ [3]). The arrows mark the possible positions of the Wall separating the high, low density Cells with opposing wind directions.

Well above the Cells' altitudes such as seen by CHAMP's (at $400 \mathrm{~km}$ ), enhanced electron density and temperatures, ion and neutral velocities are predicted due to soft electron precipitation $(\sim 500 \mathrm{ev})$. This particle precipitation in the Cusps inputs energy to the electrons which move upwards creating ambipolar electric fields, which in turn pull ions upwards [15], with speeds exceeding even $500 \mathrm{~m} / \mathrm{s}$ and thus dragging neutrals with them all within 10-15 minutes [10]. Electron temperature is enhanced within about an hour. The increased ion upwelling increases neutral density to maintain charge neutrality [7]. Just direct energy input to neutrals from joule heating and ion drag gives only small enhancements in the neutral densities [2]. The dependence of the thermospheric wind and the field-aligned currents on the By and $\mathrm{Bz}$ components of the interplanetary magnetic field at CHAMP's altitude have been studied recently by Huang et al [4] and Kersvalishvili and Luhr [5]. In light of this existing morphology of these Cells at high latitudes, a simplified linearized theoretical treatment is used to see if the observed rise and descent of emissions in the thermosphere by WINDII-UARS could be explained in the next section.

\section{Simple Linearized Theoretical Treatment}

Here we examine the simple dynamical behavior of the idealized 'narrow' Cells in high latitudinal regions, in 
transporting neutral gas downwards in the convergence region and upwards in the divergence region, in a linearized fashion. We will ignore for the time being Coriolis and iondrag forces during transport process, which are especially important for large spatial sizes of these Cells and one has to deal with appropriate momentum, continuity and energy equations. This will be the subject matter in a future study.

The ambient atmosphere in hydrostatic equilibrium can be represented for unit mass by the equation:

$$
0=-\mathrm{g}-1 / \rho_{\mathrm{a}} \cdot \mathrm{dp} / \mathrm{dz}
$$

where $\rho_{\mathrm{a}}$ is the ambient density, $g$ the gravitational acceleration and $\mathrm{p}$ the pressure at a height $\mathrm{z}$. If a Cell is not in a hydrostatic equilibrium with the ambient atmosphere, it is 'unstable' and its vertical acceleration can be represented by the equation:

$$
\mathrm{d}^{2} \mathrm{z} / \mathrm{dt}^{2}=-\mathrm{g}-1 / \rho_{\mathrm{c}} \cdot \mathrm{dp} / \mathrm{dz}
$$

assuming that the pressure acting on the cell is always adjusted to the ambient one at the same level. Here $\rho_{c}$ is the Cell's density. Let the density and the temperature of the cell formed, $\rho_{c}$ and $T_{c}$ be in equilibrium with the ambient thermosphere with corresponding density and temperature as $\rho_{a}$ and $T_{a}$ at height $\mathrm{z}$. Now eliminating $\mathrm{dp} / \mathrm{dz}$ from $(1,2)$ above or simply by applying Archimedean principle and the Newton's second law, the Cell's equation of motion can be written as:

$$
\mathrm{d}^{2} \mathrm{z} / \mathrm{d}^{2} \mathrm{t}=\mathrm{g}\left(\rho_{\mathrm{a}}-\rho_{\mathrm{c}}\right) / \rho_{\mathrm{c}}
$$

In case of the ideal gas law, equation (3) can also be written in terms of temperature as:

$$
d^{2} \mathrm{z} / \mathrm{d}^{2} \mathrm{t}=\mathrm{g}\left(\mathrm{T}_{\mathrm{c}}-\mathrm{T}_{\mathrm{a}}\right) / \mathrm{T}_{\mathrm{a}}
$$

As we can see from equation $(3,4)$ in the case of convergence, the Cell in the high density structure is such that $\rho_{\mathrm{c}}>\rho_{\mathrm{a}} \quad\left(\mathrm{T}_{\mathrm{a}}>\mathrm{T}_{\mathrm{c}}\right)$, so it will accelerate downwards transporting neutral gas to a lower height where it will encounter a density or temperature equal to that of the ambient atmosphere and may disappear. This will increase the airglow emission at lower heights. Similarly, in the case of divergence, the Cell is in a low density structure, $\rho_{\mathrm{c}}<\rho_{\mathrm{a}}$ $\left(\mathrm{T}_{\mathrm{c}}>\mathrm{T}_{\mathrm{a}}\right)$, so it will move upwards transporting neutral gas and thus emissions, and when it encounters an equal ambient density or temperature then again it may disappear.

If the Cell's velocity, dz/dt is zero at the cell height say, $\mathrm{z}_{0}$, and assuming constant $T_{c}$ and $T_{a}$ with height, then the integration of equation (4) with time ' $t$ ' will yield

$$
\Delta z=\left[\mathrm{g}\left(\mathrm{T}_{\mathrm{c}}-\mathrm{T}_{\mathrm{a}}\right) / \mathrm{T}_{\mathrm{a}}\right] \mathrm{t}^{2} / 2
$$

Equation (5) shows that the transport time depends on the ratio $\left(\mathrm{T}_{\mathrm{c}} / \mathrm{T}_{\mathrm{a}}\right)$ and $\Delta z$, the height travelled by the Cell to transport the neutrals. Adopting $\mathrm{T}_{\mathrm{a}} \sim 800 \mathrm{~K}$ and assuming $\mathrm{T}_{\mathrm{c}}$ $\sim 10 \%$ less than $\mathrm{Ta}$ in the thermosphere during low solar and geomagnetic activity, a part of the high density Cell can transport neutral gas and thus emissions by say, about 100 $\mathrm{km}$ downwards in about $8 \mathrm{~min}$, in an idealized case. Similarly assuming $\mathrm{Tc} \sim 10 \%$ greater than $\mathrm{Ta}$, a low density Cell can transport neutral gas and thus emissions by about $100 \mathrm{~km}$ upwards in about the same time. For the WINDII observations in 1996 for the same low solar activity but at highly disturbed geomagnetic activity (Ap 57, Kp 7), on neglecting the latitudinal variations at high latitudes in the geomagnetic activity effects, the changes in the thermospheric temperature can be represented as [9]):

$$
\Delta \mathrm{T}_{\mathrm{a}}=21.4 \mathrm{Kp}+0.03 \exp (\mathrm{Kp})
$$

This also yields also about $7 \mathrm{~min}$ for the Cell to transport the neutrals under identical conditions. The Cells responsible for the transport of the neutrals could belong to Stable or Unstable types. From equation (5), if $\left(\mathrm{T}_{\mathrm{c}} / \mathrm{T}_{\mathrm{a}}\right)$ is $>1$ or $<1$ during its path then the Cell will keep on moving up or down in the same direction respectively before it disappears, and is called the Unstable type. If during its path $\left(\mathrm{T}_{\mathrm{c}} / \mathrm{T}_{\mathrm{a}}\right)$ changes from $>1$ to $<1$ or vice versa, the Cell will reverse its path to where it started and will be of the Stable type. After these Cells disappear during transport, other Cells will keep the process going on at the latitudes and times of the high density or low density Cells as these are permanent features. Different Cells start at different heights and end at different heights. In case, if the initial Cell's velocity is non-zero, equation (5) will take the form

$$
\Delta z=\mathrm{v}_{0} \mathrm{t}+\mathrm{g}\left[\left(\mathrm{T}_{\mathrm{c}}-\mathrm{T}_{\mathrm{a}}\right) / \mathrm{T}_{\mathrm{a}}\right] \mathrm{t}^{2} / 2
$$

and

$$
\Delta \mathrm{z}=\mathrm{v}_{0} \mathrm{t}+\mathrm{g}\left[\left(\rho_{\mathrm{a}}-\rho_{\mathrm{c}}\right) / \rho_{\mathrm{c}}\right] \mathrm{t}^{2} / 2
$$

In other words, $\Delta \mathrm{z}$ will also depend on the initial velocity of the Cell, $\mathrm{v}_{0}$.

\section{Comparison of the WINDII Observations with the Models}

The Wall observed around local noon in the winds during October, 1995 in the northern hemisphere (magnetic pole at $80^{\circ} \mathrm{N},-70^{\circ} \mathrm{W}$ geographic) for low solar activity and moderate geomagnetic disturbed periods is around $65^{\circ}$ geographic latitude and about $250^{\circ} \mathrm{E}$ longitude, on average [13]. In figure (1b) for moderate disturbed period, the Wall in the atmospheric density is shown by an arrow at around 9 LT and at $5 \mathrm{LT}$ local times. The local noon at $250^{\circ} \mathrm{E}$ will put the observed Wall in zonal wind at about $320^{\circ} \mathrm{E}$ or around $9 \mathrm{LT}$ in the figure, close to the low density Cell area. That means that these low density Cells are capable of transporting neutrals and thus emissions to higher altitudes, probably close to the observed ones in zonal wind velocity enhancement around $200-250 \mathrm{~km}$ altitude range.

As far as the southern hemisphere in March, 1996 is concerned (magnetic pole $-74.5^{\circ} \mathrm{S}, 127^{\circ}$ geographic), the Wall observed for low solar activity and mild geomagnetic activity is around $65^{\circ} \mathrm{S}$ and $150^{\circ} \mathrm{E}$ [13] Though the model polar diagram for low solar and geomagnetic activity in the southern hemisphere is not available at the time, we can roughly compare these observations with the ones in figure 
(1b) for mild geomagnetic activity in the northern hemisphere as the structures of the Cells are similar in both the hemispheres. The Wall at $150^{\circ} \mathrm{E}$ close to the longitude of the magnetic pole, will put it around $13 \mathrm{LT}$ in the high density Cell area. At this time the observed emissions are enhanced to much lower altitudes by high density Cells reaching to about $100 \mathrm{~km}$, lower by up to $100 \mathrm{~km}$ than in the enhancements of the zonal and meridional winds.

The upper atmospheric observation in summer solstice, January, 1995 in Red line emission $\left[\mathrm{O}\left({ }^{1} \mathrm{D}\right)\right.$ at $\left.630 \mathrm{~nm}\right]$ from WINDII in the southern hemisphere have also been recently reported by Shepherd et al [14]. They observed an increase in the emissions at around $200 \mathrm{~km}$ in the $100-150^{\circ} \mathrm{E}$ longitudinal zone at high latitudes in the southern hemisphere for the period of low solar activity (F10.7 $\left.72 \times 10^{-11} \mathrm{w} / \mathrm{m} 2 / \mathrm{c} / \mathrm{s}\right)$ and mild geomagnetic activity $(7<\mathrm{Ap}<30)$. We can see from the figure (1b) that this area lies again in the domain of the high density Cells around 13 LT assuming the Cell structures are similar in both the hemispheres. The Cells in the high density region will transport neutrals to lower altitudes, this leads to a deficit of neutrals in upper thermosphere leading to an increase in Red line intensity there since it depends inversely on the densities of molecular oxygen and nitrogen.

\section{Results and Discussions}

The $\mathrm{O}\left({ }^{1} \mathrm{~S},{ }^{1} \mathrm{D}\right)$ observations by WINDII on the UARS satellite have shown a convergence region in the westward zonal winds and a divergence region down the Wall in the east side zonal winds in the high latitudinal region during daytime implying vertical flows of the neutral gas. As a result depending on the overlap of the Wall on the high or low density sides, the emissions were enhanced and moved down on the west side, and moved up on the east side for the existing low solar and mild geomagnetic conditions. It is shown that in the thermospheric region of $130-300 \mathrm{~km}$, the Cells in high / low density regions almost overlap the convergence / divergence structure in the density adjacent to the Wall, and are able to move neutrals from higher to lower and lower to higher altitudes respectively. These Cells were deduced by the NCAR-TIGCM models and other satellite observations below $300 \mathrm{~km}$. These cells seem to occur for all solar and geomagnetic conditions in both hemispheres, with additional low density dusk and high density night Cells for higher solar and geomagnetic activities. The Cells are not observed above about $300 \mathrm{~km}$.

The WINDII observations have been compared with these models and discussed. Following a simplified treatment more suitable for 'narrow' Cells by neglecting the non-linear effects like ion-drags, Coriolis forces which are important for large spatial thermospheric Cells, the vertical transport due to these or part of these Cells in the convergence region enhancing the emission even to the lower thermosphere, and in the divergence region raising the emission to higher altitudes is shown. No such Cells transporting neutrals will exist once their temperature or density equalizes with that of the ambient atmosphere. After that other neutral Cells available at other heights will transport the neutrals at the time and latitude of these Cells. The distance travelled by these Cells in transporting the neutral gas vertically is larger, larger the temperature difference between the Cell and the ambient displaced atmosphere. The ideal travel time of the Cells from equation (5) to transfer neutrals from upper to the lower thermosphere or vice versa is around 8 minutes for heights of say, about $100 \mathrm{~km}$ for solar and geomagnetic quiet periods.

Here the implications of the thermospheric Cells in the density and winds have been mainly discussed for vertical movement of emissions for low and mild solar activity and geomagnetic conditions. As mentioned before that in TIGCM models, the Wall separating the low and high density Cells tend to be more north-south aligned rather than east-west as the solar and geomagnetic activity increases. In addition a high nighttime density and a low dusk density Cell start appearing. Therefore it will be worthwhile in future studies to look into WINDII and ISIS data on these emissions and their response for these conditions.

\section{Conclusions}

It has been shown here on the basis of a simplified treatment of the vertical motions of narrow high and low density neutral Cells at high latitudes in the earth's thermosphere that these Cells contribute to the vertical transport of the emissions from the atomic oxygen as observed by WINDII instrument on UAR satellite. The emissions are transported downwards in the region of high density Cells and upwards in the region of low density Cells in the daytime and morning sectors respectively. Once the densities of these Cells equalizes with that of the ambient atmosphere, the transport ceases and other Cells may partake in this transport process. An idealized time is about $8 \mathrm{~min}$ for a $100 \mathrm{~km}$ transport for quiet solar and geomagnetic conditions. A further analysis of the data in intended to be carried out to see such emission transport in the region of high density Cells during nighttime and low density Cells during dusk respectively.

\section{Acknowledgements}

The author thanks Professor G. G. Shepherd for many useful discussions.

\section{References}

[1] Caspers, T and G. W. Prolss, Thermospheric density cells at high latitudes, Adv. Space Res., 24, 1433, 1999.

[2] Clemmons, J. H, J. H. Hecht, D. R. Salem and D. J. Strickland, Thermospheric densities $\mathrm{n}$ the earth's magnetic cuspas observed by the Streak mission, Geo. Res. Letters, 35, L24103, 2008.

[3] Crowley, G, J. Schoendorf, R. Roble and F. A. Marcos, Cellular structures in the high-latitude thermosphere, J. Geophys. Res., 101, 211, 1996. 
[4] Huang, H. Luhr, H. Wang and C. Xiong, The relationship of high latitude thermospheric wind with ionospheric horizontal current as observed by CHAMP satellite, J. Geophys. Res., 122, 12378, 2017.

[5] Kervalishvili, G. N and H. Luhr, Climatology of zonal wind and large scale FAC with respect to the density anomaly in the cusp region: seasonal, solar cycle and IMF-By dependence, Ann. Geophys., 32, 249, 2014.

[6] Liu, H, H. Luhr, V. Henize and W. Kohler, Global distribution of thermospheric total mass density derived from CHAMP, J. Geophys. Res (Space Physics), 110, A04301, 2005.

[7] Luhr, H, M. Rother, W. Kohler, P. Ritter and P. Grunwaldt, Thermospheric up welling in the cusp region: evidence from CHAMP observations, Geo. Res. Letters., 31, L06805, 2004.

[8] Marcos, F. A and E. R. Swift, Application of the satellite triaxial accelerometer experiment to atmospheric and wind studies, AFGL Tech. Report, TR-82-0091, I 51, 1982.

[9] Roemer, M, Recent observational results of the thermosphere and exosphere, Part 4: CIRA (Cospar International Reference Atmosphere), Akademie Verlag, 1972.

[10] Sadler, F. B, M. Lessard, E. Lund, A. Otto and H. Luhr,
Auroral precipitation / ion upwelling as a driver of neutral density enhancement in the cusp, J. Atm. Solar Terr. Physics, 87, 82, 2012.

[11] Schoendorf, J, G. Crowley, R. G. Roble and F. A. Marcos, Neutral density cells in the high latitude thermosphere-1: Solar maximum cell morphology and data analysis, J. Atm. Terr. Physics, 58, 1751, 1996-1.

[12] Schoendorf, J, G. Crowley and R. G. Roble, Neutral density cells in the high latitude thermosphere-2, J. Atm. Terr. Physics, 58, 1769, 1996-2.

[13] Shepherd, G. G and M. G. Shepherd, High latitude observations of a localized wind wall and its coupling to the lower thermosphere, Geo. Res. Letters, 45, 4586, 2018.

[14] Shepherd, M, G. Shepherd and M. Codresu, Perturbations of $\mathrm{O}\left({ }^{1} \mathrm{D}\right)$ VER, Temperature, Atomic oxygen and TEC at high Southern latitudes, J. Geophys. Res (Space Physics), 10.1029, A026480, 2019.

[15] Su, Y. J, R. G. Caton, J. L. Horwitz, P. G. Richards, Systematic modeling of soft electron precipitation effects on high latitude F-region and topside ionospheric up flows, J. Geophys. Res., 104, 153, 1999. 